\title{
ARRAIGO Y DESARRAIGO
}

Clara Vedoya de Guillén

$$
\text { - I - }
$$

La Literatura clásica, por ser tal, inscribe, a través de sus situaciones puntuales, esa realidad compleja y sublime que se llama hombre. Por eso hemos dicho siempre, a lo largo de nuestra muy langa carrera docente, que la Literatura griega y romana es clásica - y no muerta, como algunos quieren llamarla - porque es universal. Aquileo, Orestes, Edipo, Eneas o Tumo, son más que reyes o guerreros de su momento y lugar: son hombres que se debaten por el honor, la venganza, la búsqueda de la verdad, de un destino o de su reivindicación. Son hombres, y expresan en su circunstancia los problemas y las pasiones de todo hombre, cualesquiera sean sus coordinadas témporo-espaciales. Eso es lo que los griegos llaman \&́petń y los romanos, "Humanitas". Por eso, si abrimos al azar algunas páginas de las obras clásicas, nos encontramos con autores de todas las épocas que cantan, narran o hacen vida - según el género en que se exprese - esa misma realidad humana.

Como chaqueña por adopción, quiero que nos detengamos por un momento a considerar una misma actitud vivida en los inicios de la legendaria Roma por Eneas y sus compañeros, y por los hombres y mujeres que nos dieron el ser chaqueño. Esa actitud es la del arraigo en un mundo nuevo, lo cual trae aparejado, lógicamente, un anterior y doloroso desarraigo.

$$
-\| \text { - }
$$

Son los hombres de Eneas, troyanos vencidos, arribando a las costas latinas que les han sido destinadas por los dioses (Virgilio: Eneida, VII y VIII), y son los hombres del FRIUL "subiendo por el Río Negro" en pos de nuevos horizontes, que nos muestra un poeta, también chaqueño por adopción: Don Aledo Luis Meloni, en su breve poema La Aventura; denso poema que en simples cinco cuartetas expresa el mundo de emociones, anhelos y esperanzas de quienes con increible empuje y entereza han emprendido una aventura casi imposible (pensemos lo que serian estos montes virgenes hace más de cien años, tal como nos describe Dobroshöffer en "De Abiponibus").

En este breve análisis veremos:

1. Las motivaciones de este desarraigo - arraigo

2. Lo que dejan los protagonistas

3. Lo que encuentran

4. Cómo se produce este arraigo

5. La respuesta del nuevo mundo

6. El futuro que vislumbran 


\section{Las motivaciones}

Virgilio vive en una Roma que ha perdido la fe y que sufre mil influencias del mundo que ella conquistó y que la desintegra. Quiere devolverle los valores de su antigua "virtus". Por eso su personaje, Eneas, es pius -principal epíteto-, piedad que significa la justa relación del hombre con los dioses. De ahí que vemos como lógica que la razón por la que Eneas y sus compañeros arriban por fin a las costas del Lacio -tras muchas peripecias que siguen las huellas de Odiseo-, sea el cumplimiento de un destino señalado por los dioses. Cuando Latino, rey del lugar, les da la bienvenida, llioneo le explica el motivo de la presencia de ese puñado de hombres allí:

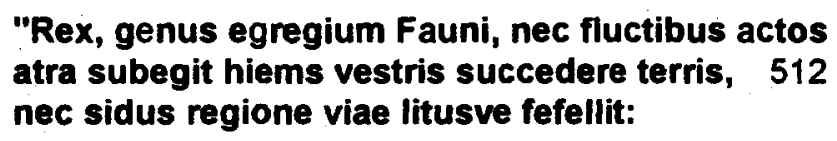

"Rex, genus egregium Fauni, nec fluctibus actos atra subegit hiems vestris succedere terris, 512 nec sidus regione viae litusve fefellit:

Sed nos fata deum vestras exquirere terras imperiis egere suis..."

(Aeneidos, Lib VII)

"Oh rey, linaje ilustre de Fauno: ni una negra tormenta nos obligó a arribar a vuestras tierras, ni las estrellas ni las costas nos han hecho equivocar el rumbo (...) Pero los hados de los dioses nos forzaron, con sus mandatos, a buscar vuestras tierras."

El puñado de hombres y mujeres "venidos desde el Friul" que nos presenta Meloni, viene también cumpliendo un destino de grandeza del que tal vez ni ellos mismos hayan sido demasiado conscientes; Meloni, con la capacidad de síntesis que lo caracteriza, dice solamente:

\section{"La tierra nueva era un señuelo verde, la forma vegetal de Dios."}

Un Dios que los ha llamado desde esa tierra nueva, ese señuelo que toma la forma de los montes chaqueños. Es Dios, es una fuerza trascendente quien mueve los destinos de los hombres. Siempre. Aún sin que los protagonistas, el hombre, sean conscientes, acepten o vivan ese destino superior. Es la actitud de tantos inmigrantes que durante décadas fueron arribando a las costas rioplatenses, atraídos por la feracidad de sus tierras y que son, en gran medida, los que forjaron nuestro serargentinos: simbiosis inefable e irrepetible de indio, español y gringo.

$$
- \text { IV - }
$$




\section{Lo que dejan los protagonistas}

¿Qué han dejado atrás esos hombres que llegan "pulsi regni" (arrojados del reino, suplicantes del nuevo mundo?

\section{"manibus vittas ac verba precantia" $(235, \mathrm{VII})$}

"con ramas de olivo en las manos y palabras suplicantes."

Todo el Libro II es una minuciosa descripción que hace Eneas ante Dido de la destrucción de Troya; destrucción que le provoca:

"infandum removere dolorem"

"remover el infando dolor."

el dolor de la Patria perdida y asolada:

"Tum vero omne mihi visum considere in ignis

IIlium, et ex uno verti Neptunia Troia" (II, 624/5)

"entonces fue visto por mi todo llión hundirse entre fuegos y a la neptunia derribarse desde sus cimientos." destructores.

Dolor que haría estremecer hasta las lágrimas aún a los mismos dánaos

Dolor que también sienten quienes, movidos por ese "señuelo verde, imagen vegetal de Dios", sienten que

"La ausencia les dolía en el costado"

ausencia de la Patria, de la lengua, de la familia; en fin, de los valores que los sustentaban "allende el mar".

Meloni no explicita, como lo hace Virgilio, las escenas de la Patria perdida, dice simplemente:

"Lo que habian dejado allende el mar"

y en ese silencio, en el neutro $\underline{10}$, podemos adivinar el mundo dejado atrás.

$$
-\mathbf{v} \text { - }
$$

\section{Lo que encuentran}

$Y$ llegan, por fin, ambos puñados de hombres, nostálgicos de la tierra ya lejana, pero decididos a emprender esa nueva aventura. $Y$ nuevamente surge, espontáneo, el paralelo: 


\section{"Labitur uncta vadis abies; mirantur et undae, miratur nemus..." (VIII, 91/92)}

"Se deslizan por aguas favorables las naves de abeto con plácido rumor; maravillanse las selvas".

ante esos otrora guerreros que suben por el río Tiber en busca de una alianza con el rey de aquellos parajes, asiento de la futura Roma.

\section{"Mientras subian por el rio Negro \\ entre el ramaje en flor del Litoral..."}

esos otros hombres que llegan, en paz, a las tierras donde se asentaría la pujante $-y$ tal vez hoy dolorida- Resistencia.

La Naturaleza, "maravillada", contempla a los intrépidos y los acoge.

Pero Eneas y los suyos han de liberar todavía una larga, cruel guerra con los habitantes de esas tierras que, engañados por una diosa, se desdicen de su primera actitud receptiva. Guerra en la que Virgilio hace resonar los ecos de La llíada, la gesta heroica de los griegos.

También los hombres del Friul llegados a estas tierras deberán librar una guerra; sin sangre, silenciosa:

\section{"Cuando midieron la primera melga, cuando partieron el primer terrón ellos inauguraron la mañana En cada reja se asombraba el sol."}

y otra vez el sol chaqueño, como las selvas latinas, se asombran ante los recién llegados. Ambas embarcaciones avanzan, lenes, en la tierra nueva que los recibe:

"...et laetus fluvio succedit opaco" (VII, 36)

"gozoso penetra en el sombreado río"

Eneas y sus "jóvenes escogidos, valientes y briosos", arriban, por fin, a las tierras que los dioses les han asignado para fundar una nación gloriosa, llevados por tantas vicisitudes, fruto de los caprichos divinos.

Otros hombres, soñadores de una gran ciudad, suben por nuestro río Negro,

"entre el ramaje en flor del Litoral"

Unos y otros, los hombres de llión y los del Friul, sienten la caricia refrescante de la vegetación nueva que los recibe con su sombra.

$-\mathbf{V} \mathbf{~ - ~}$

\section{El arraigo}


Creo no equivocarme si afirmo que ambos pueblos no tandan en afincarse en esos nuevos horizontes a los que son llevados por fuerzas, ya to dijimos, superiores. Serán los dioses -simple explicación mítica de las acciones humanas- quienes vuelcan en los hombres sus pasiones encontradas y los hacen juguetes de sus enconos; o será ese "sen̂uelo verde, imagen vegetal de Dios".

Pero creo también poder afirmar que el proceso de ese afincamiento es inverso en ambos casos:

Eneas y sus compañeros sienten que

"Hic domus, haec patria est" (VII,122)

"Ésta es la casa, ésta la patria."

y son recibidos por el rey Latino, deseoso de un matrimonio para su hija, "la virgen Lavinia", que lo ha de emparentar con los dioses. Colma de presentes a la embajada de paz enviada por Eneas, ofreciéndole la mano de su hija. Pronto los troyanos se aprestan a levantar en ese solar la nueva llión:

\section{"Ipse humili designat moenia fossa molitu locum" (VII, 157/8)}

"Él mismo construye en la tierra la fosa de la muralla y señala el lugar".

Pero -otra vez asistimos a la visión teocéntrica de ese mundo mítico- es la voluntad de los dioses quien interfiere en las acciones de los hombres: en un largo pasaje del Libro VII (286/322) Juno, la esposa de Júpiter despechada por la elección adversa que hiciera el troyano Paris en favor de Venus, maquina su última venganza por la que, ya que no podrá torcer los designios de los hados (Flectere nequeo superos: "No logro doblegar a los dioses" -VII, 312), logrará, al menos, para Eneas, como nuevo Paris,

"Funestaque iterum recidiva in Pergamo taedae" (VII, 322)

"Y nuevamente (Venus será) una tea funesta para la renaciente Troya".

Los restantes Libros de La Eneida son una pormenorizada narración de esa cruenta guerra entre rútulos y troyanos -otra vez- por la conquista de una mujer. Dura lucha que Virgilio resume preanunciándola en ese que alguna vez he llamado "proemio interior" de la obra:

"Tu vatem, tu, diva, mone. Dicam horrida bella, dicam acies actosque animis in funera reges Tyrrhenamque manum totamque sub arma coactam Hesperiam." (VII, 41/44) 
"Tú, oh diosa, inspirame: cantaré hórridos combates, celebraré los ejércitos y los reyes que la ira excitó a la mortandad, y las huestes tirrenas, y la Italia toda respirando guerra".

Los hombres del Friul que se asientan en estas riberas virgenes deberán, también, librar una larga, dura lucha; pero no será, como la de sus ancestros, cruenta:

Después le hurtaron su secreto al monte

y partieron la tierra como el pan;

y ladrillo a ladrillo levantaron

la ciudad que soñaron al llegar."

dice la poesia de Meloni en la versión definitiva de 1980. En la primera versión, de1965, ha mostrado a esos valientes "midiendo la primera melga, partiendo el primer terrón". Ambas escenas nos hablan de otra guerra, no menos valiente por ser más silenciosa: la de los hombres y mujeres que se enfrentan a los elementos de la naturaleza y van forjando, "ladrillo a ladrillo" un futuro de paz para su pueblo.

Porque la vida es lucha, y esa lucha es el tributo que se nos pide, muchas veces, para lograr eso que hemos llamado "arraigo".

$$
- \text { VII - }
$$

\section{La respuesta del nuevo mundo}

Tal vez el pasaje de La Eneida que mejor muestra la razón de ser de tantas jornadas dolorosas vividas por Eneas y los suyos hasta llegar al Lacio, de tantas jornadas dolorosas pasadas en guerra, esté dado en el Libro VI, cuando el héroe se encuentra con su padre Anquises y éste le muestra la noble progenie de su estirpe, hasta llegar a

"Hic vir, hic est, tibi quem promitti saepius audis.

Augustus Caesar, divi genus, aurea condet saecula..." (VI, 791/3)

"Éste es el varón, éste es el que muchas veces oyes que te está prometido, César Augusto, raza de dioses, que restaurará en el Lacio los siglos de oro."

Ésa es la respuesta del mundo nuevo al que han llegado esos hombres intrépidos que se saben portadores de un destino superior: un Imperio que "está más allá del camino de los astros, más allá de la ruta del sol..."

También nuestros pioneros, soñadores de una ciudad donde sólo había monte virgen, lograron su intento:

$$
\begin{aligned}
& \text { "Ahora crece sobre su leyenda } \\
& \text { la ciudad que soñaron al llegar; } \\
& \text { corazón del Nordeste, mano abierta } \\
& \text { hacia los cuatro rumbos de la paz." }
\end{aligned}
$$


pinta la edición '65: una ciudad que también se abre más allá de sus propios límites, abierta "hacia los cuatro rumbos de la paz", con "mano abierta" para recibir a todos los hombres y mujeres que, tras ellos, fueron amalgamando lo que otro poeta chaqueño llamó "crisol de razas".

Ambas gestas, vividas por héroes de distinta dimensión, desembocan en un futuro de grandeza.

- VIII -

\section{El futuro}

En la escena a la que aludiamos, del encuentro de Eneas con su padre, Virgilio da a Roma, señora y diosa del mundo en su siglo, aldea de pastores y labriegos en sus origenes, una cuna de raza divina en Julo, nieto de la diosa Venus. Mira hacia adelante y ve desfilar su descendencia, y ve la auténtica misión de Roma:

"Tu regere imperio populos, Romane, memento (haec tibi erunt artes), pacisque imponere morem, parcere subiectis et debellare superbos." (VI, 851/3)

"Tú, romano, procura gobernar los pueblos con autoridad -ésas serán tus artes-, establecer condiciones de paz, perdonar a los sometidos y derribar a los soberbios."

Ése es el futuro de Roma: gobernar los pueblos, establecer la paz. Roma, conquistadora del mundo, que supo realizar en sus conquistas algo único e irrepetido: civilizó sin arrasar, romanizó respetando las culturas vernáculas, levantó un mundo unificado en su variedad, que haría posible el resurgimiento de un mundo cristiano.

Ese puñado de hombres y mujeres que "suben entre el ramaje en flor del Litoral", 10 hacen mirando más allá de esas "primeras melgas" o "primeros terrones"; ellos "inauguraron la mañana", dejan

\section{"En la memoria de la patria nueva quedó historiada como en haz de luz, la fecha liminar de la aventura de los hombres venidos desde el Friul."}

Porque lo que hacen ellos es, justamente, eso: marcar una "fecha liminar", marcar el comienzo de esa "ciudad que soñaron al llegar", señalar un camino "abierto hacia los cuatro rumbos". Meloni, poeta chaqueño por adopción, que ha sentido él también esa vivencia casi inenarrable del arraigo en una tierra acogedora, es quizás por eso idóneo para mostramos a quienes, al llegar y establecerse en estas tierras,

"olvidaron la ruta de regreso

y dejaron anclado el corazón." 


$$
-\mid \mathbf{X}-
$$

Arraigo y desarraigo: es el drama no sólo de grupos de hombres y mujeres que viven una circunstancia, sea de quienes arriban ai Lacio traídos por ios dioses favorables, sea de quienes llegan a este litoral llamados por un "señuelo verde, imagen vegetal de Dios". Es el drama de el hombre, fluctuante entre un mundo concreto de realidades vanales y temporales y la inagotable sed de eternidad. Un hombre siempre desarraigado en busca de arraigarse en un mundo mejor.

En esta hora de incertidumbre que vivimos, las obras de literatura nos muestran al hombre de todos los tiempos que con fe es capaz de mirar hacia adelante, de soñar con un futuro, de forjar una raza y marcar los "rumbos de la paz". 